\title{
Rapid Method for the Detection of Cystic Fibrosis of the Pancreas in Children
}

\author{
B. A. SAGGERS, DAVID LAWSON, J. STERN, and A. C. EDGSON \\ From Queen Mary's Hospital for Children, Carshalton, Surrey, and Electronic Instruments Ltd., Richmond, Surrey
}

One of the main criteria for the diagnosis of cystic fibrosis of the pancreas is the presence of a raised sweat sodium level in the patient (Di Sant' Agnese, Darling, Perera, and Shea, 1953). The standard method of using pilocarpine iontophoresis to produce sweat (Gibson and Cooke, 1959), and estimating the sodium present by conductivity or flame photometry, is a workable technique but has some drawbacks. Considerable discomfort is experienced by some patients and the process is timeconsuming, as it takes at least $\mathbf{3 0}$ minutes to obtain sufficient sweat for a reliable sodium determination. Pilocarpine iontophoresis is therefore not suitable for routine use as a screening test on large numbers of patients.

The use of a sodium responsive electrode for direct readings of the sodium concentration of sweat has not been successful in our hands (Goldbloom and Sekelj, 1964). We found that iontophoresis was necessary before reliable readings could be obtained. Difficulties also occurred due to sweat evaporation and variations in skin temperature.

McGrady and Bessman (1955) and Johnston (1956) have found that cystic fibrosis patients have a raised parotid saliva sodium level compared with that of normal subjects. We have devised a method for measuring the sodium concentration of unstimulated parotid saliva using a micro-dual sodium electrode, which is simple and reliable in children and adults.

The results are presented of a trial with this electrode on normal subjects, cystic fibrosis heterozygotes, and cystic fibrosis homozygotes.

\section{Material and Methods}

The age ranges of the subjects investigated were as follows: normals (who could be expected to include about $4 \%$ of unknown heterozygotes), 1-48 years (mean 24.9 years); heterozygotes, $25-49$ years (mean 35.6 years); and homozygotes, 1-19 years (mean $6 \cdot 24$ years).

\footnotetext{
Received August 16, 1966.
}

It is hoped in future to develop this technique for the rapid screening of the newborn.

The electrode. The sodium-responsive electrode used in this survey was developed in the laboratories of Electronic Instruments Ltd. as a modification of a Jena micro-dual-pH electrode (Fig. 1). When not in use the electrode was stored with the bulb immersed in $0 \cdot 1 \mathrm{M} \mathrm{NaCl}$.

The electrode system was used with an E.I.L. Vibron Blood $p \mathrm{H}$ Meter, model 48B; readings of $\mathrm{pNa}$ were taken on the $p \mathrm{H} 6 \cdot 6-8 \cdot 0$ scale.

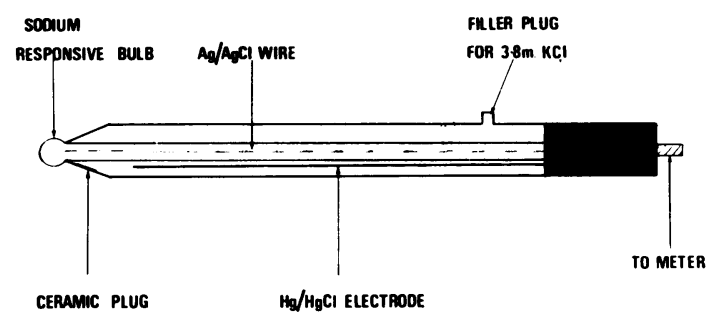

FIG. 1.-A micro-dual sodium responsive electrode for the determination of parotid saliva $\mathrm{pNa}$ values.

Standardization of the electrode. The electrode system and the $p \mathrm{H}$ meter were standardized, using sodium chloride solutions of $100,75,25$, and $10 \mathrm{mEq}$ $\mathrm{Na}^{+} /$litre. The readings obtained from the standard solutions were marked on the $p \mathrm{H}$ scale and a standard curve of $\log \mathrm{mEq} \mathrm{Na}{ }^{+} /$litre against $p \mathrm{H}$ reading was plotted.

The $p \mathrm{H}$ meter when used with the sodium electrode did not give a fixed check point on the metre scale. The calibration of the system was therefore checked daily with a standard sodium chloride solution of $50 \mathrm{mEq}$ $\mathrm{Na}^{+} /$litre.

Disinfection of the electrode. As the electrode was to be used in the mouth to measure the sodium concentration of parotid saliva, it was necessary to find a quick and effective means of sterilization that would not affect its working. The effect of wiping the electrode with 


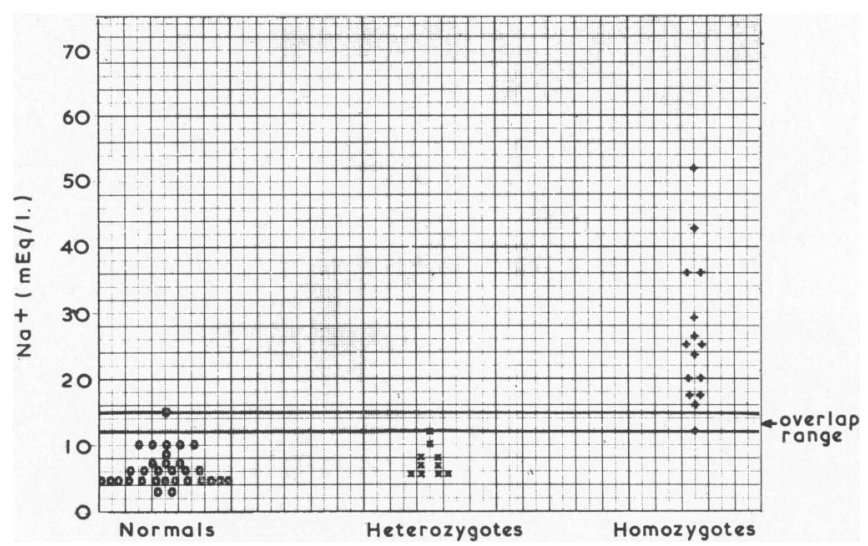

Fig. 2.-A comparison of the unstimulated parotid saliva sodium levels obtained from normal subjects, cystic fibrosis heterozygotes, and cystic fibrosis homozygotes, using a micro-dual sodium electrode.

various sterilizing agents after infection with overnight broth cultures of Aerobacter aerogenes, a coliform, Proteus sp., Pseudomonas aerugenosa, Staphylococcus aureus, and a haemolytic streptococcus, was determined. The most reliable agent tested was $70 \%$ isopropanol: this did not affect the working of the electrode provided that after wiping with isopropanol the electrode was immediately immersed in $0 \cdot 1 \mathrm{M} \mathrm{NaCl}$. The sterilization of the electrode in this survey was therefore done by wiping the electrode with a pad soaked in 70\% isopropanol (Medi-Swab, Medi-Pack Ltd.).

Measurement of sodium content of parotid saliva. The $p H$ meter was first adjusted with the temperature compensating dial to read sodium concentrations at $37^{\circ} \mathrm{C}$. and the saliva was tested as follows: the electrode was removed from the $0 \cdot 1 \mathrm{M} \mathrm{NaCl}$ and the excess saline was wiped from the electrode with a tissue. The electrode was then placed in the upper region of the cheek next to the second molar tooth at the opening of Stensen's duct. Care was taken to see that the ceramic plug in the reference electrode was uppermost and also that the electrode was tilted at an angle of $45^{\circ}$ to avoid any airlocks that might have formed beneath the ceramic plug. The meter was switched to the read position, and the sodium content of the parotid saliva was read after equilibrium had been reached, usually after 30 to 60 seconds. The meter was switched to the check position, the electrode removed from the mouth, wiped with a 'medi-swab', and replaced in $0 \cdot 1 \mathrm{M} \mathrm{NaCl}$.

\section{Results}

Parotid saliva sodium levels. The histogram (Fig. 2) summarizes the unstimulated parotid saliva sodium levels of 31 normal subjects, 10 cystic fibrosis heterozygotes, and 15 cystic fibrosis homozygotes.
The normal subjects gave parotid saliva sodium levels from 3-15 mEq Na+/1., with a mean value of $5.9 \pm 3.6 \mathrm{mEq} \mathrm{Na}+/ 1$. The cystic fibrosis heterozygote range of parotid saliva sodium content was between $4 \cdot 5-12 \mathrm{mEq} \mathrm{Na}+/ 1$, with a mean value of $5 \cdot 69 \pm 2 \cdot 76 \mathrm{mEq} \mathrm{Na}+/ 1$. All the heterozygotes tested were parents of known homozygotes. The parotid saliva from the cystic fibrosis homozygotes gave sodium levels from $12-52 \mathrm{mEq} \mathrm{Na}{ }^{+} / 1$., with a mean value of $27 \cdot 2-14 \cdot 2 \mathrm{mEq} \mathrm{Na}+/ 1$.

No correlation between parotid saliva sodium levels and ages of the test subjects within the groups was found in this survey.

\section{Discussion}

Comments on the electrode. The sodium responsive electrode used in this survey was well tolerated by the children tested and well suited for measuring the sodium content of parotid saliva. However, the following precautions have to be taken to avoid errors.

(1) The electrode has to be placed close to Stensen's duct, as different $\mathrm{pNa}$ readings are obtained at different points along the jaw. pNa readings taken from both sides of the jaw were found to be in satisfactory agreement.

(2) Fluctuations in the $\mathrm{pNa}$ readings were observed when the electrode was moved in the mouth, presumably due to pressure changes on the electrode surface. These fluctuations were reduced when the electrode was held steady, but fluctuations due to natural movements of the mouth by the subjects could not be avoided.

(3) Cooling of the electrode due to the subject breathing through the mouth was another cause of 


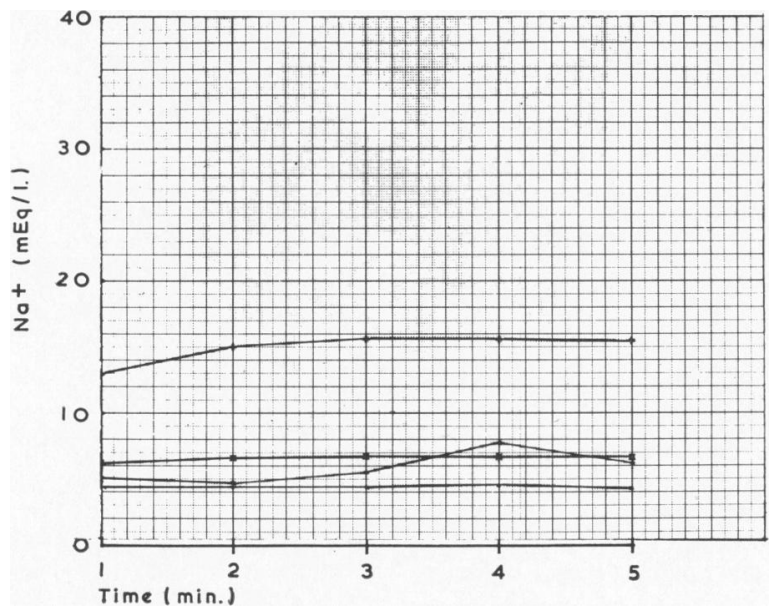

FIG. 3.-The stability of the micro-dual electrode in reading parotid saliva pNa values.

fluctuating $\mathrm{pNa}$ readings. This was avoided by encouraging normal nasal breathing.

(4) The electrode was also sensitive to violent $p H$ changes, as complete electrode insensitivity to hydrogen ions cannot technically be obtained. Any food, drink, or oral medicine which could cause marked $p \mathrm{H}$ changes in the mouth was avoided before measuring the parotid saliva pNa. Changes in the potassium or protein concentrations that might normally be expected in the mouth did not affect the $\mathrm{pNa}$ readings obtained.

Stability of the electrode. Readings of the parotid saliva sodium levels were taken at 1-minute intervals for 5 minutes in the same subject. Serial readings on a single person never varied by more than $3 \mathrm{mEq} \mathrm{Na}+/ 1$. (Fig. 3). Fluctuations occurred in all $\mathrm{pNa}$ readings but these were never more than 0.05 of a $\mathrm{pH}$ unit on the scale on either side of the equilibrium point.

\section{Conclusions}

The results of this survey showed that there was a highly significant difference between the sodium levels of the parotid saliva in normal subjects and cystic fibrosis homozygotes. Approximately $4 \%$ of the values fell in an overlap range of $12-15 \mathrm{mEq}$ $\mathrm{Na}+/ 1$. This overlap between the groups was similar to that found by McKendrick (1962) in his survey on cystic fibrosis sweat sodium levels, but it could be increased by stimulating parotid saliva flow which raises the sodium levels in normals, heterozygotes, and homozygotes. Chauncey, Levine, Kass, Schwachman, Henriques, and Kulczyeki (1962) have noted that there was only a 'borderline' significance between the sodium levels found in stimulated normal and cystic fibrosis parotid saliva.
Cystic fibrosis heterozygotes did not show any significant difference in $\mathrm{pNa}$ values from normals.

The $\mathrm{pNa}$ values of parotid saliva were not tested in neonatal children as the electrode was too large for this purpose. We hope to reduce the size of the electrode to enable a survey on neonatal children to be done, and this will be reported in due course.

Our results show that the method of detecting cystic fibrosis of the pancreas by measuring the $\mathrm{pNa}$ of unstimulated parotid saliva, using a dual sodium electrode, has possibilities as a diagnostic technique. There was a range of $\mathrm{pNa}$ values between 12 and 15 $\mathrm{mEq} \mathrm{Na}+/ 1$. which occurred in normals, heterozygotes, and homozygotes.

The authors wish to thank: Electronic Instruments Ltd. for their co-operation in the design of the electrode, Dr. W. F. Young and Dr. A. P. Norman for allowing some of their cases to be included in this study, and the Cystic Fibrosis Research Foundation Trust for a grant.

\section{REFERENCES}

Chauncey, H. H., Levine, D. M., Kass, G., Shwachman, H., Henriques, B. L., and Kulczyeki, L. L. (1962). Composition of human saliva. Parotid gland secretory rate and electrolyte concentration in children with cystic fibrosis. Arch. oral. Biol., 7, 707.

Di Sant' Agnese, P. A., Darling, R. C., Perera, G. A., and Shea, E. (1953). Abnormal electrolyte composition of sweat in cystic fibrosis of the pancreas: clinical significance and relationship to the disease. Pediatrics, 12, 549.

Gibson, L. E., and Cooke, R. E. (1959). A test for concentration of electrolytes in sweat in cystic fibrosis of the pancreas utilizing pilocarpine by iontophoresis. ibid., 23, 545 .

Goldbloom, R. B., and Sekelj, P. (1964). Application of a sodium electrode to the skin in the diagnosis of fibrocystic disease of the pancreas. Canad. med. Ass. F., 90, 474.

Johnston, W. H. (1956). Salivary electrolytes in fibrocystic disease of the pancreas. Arch. Dis. Childh., 31, 477.

McGrady, K., and Bessman, S. P. (1955). The detection of mucoviscidosis by the determination of saliva chloride. Amer. F. Dis. Child., 90, 610.

McKendrick T. (1962). Sweat sodium levels in normal subjects in fibrocystic patients and their relatives, and in chronic bronchitic patients. Lancet, 1, 183. 